\title{
Demographic Analysis and Population Catastrophes in the USSR: A Rejoinder to Barbara Anderson and Brian Silver
}

Barbara Anderson and Brian Silver have recently attempted to settle the controversy over the economic and demographic consequences of Stalinism by "demonstrating . . . how sensitive estimates of excess mortality are to the assumptions that are made about demographic data and the 'natural' course of demographic change" because they think that "the demographic evidence has been misunderstood and misused, and that the sensitivity of demographic estimates to assumptions made about the levels of mortality and fertility, as well as about the accuracy and completeness of Soviet census data and vital statistics, has not been given adequate attention." Slavic Review do not realize how difficult it is to estimate the Gulag forced labor population and to quantify the casualties caused by collectivization, Gulag, and the Terror; that they are unaware that estimates of these sorts are controversial; and that they do not fully appreciate how specific errors mar the credibility of some analysts' calculations.

The first two propositions do not warrant serious consideration. There may be some specialists who do not appreciate that the enormous disparity between Murray Feshbach's and Frank Lorimer's excess death estimates (20 million versus 5.5 million during the 1930s) indicates that the subjects under discussion are both sensitive to assumptions and controversial, but there certainly cannot be many. The merit of Anderson's and Silver's contribution therefore turns on whether they objectively prove their contention that some estimates are inferior to others.

The estimates they censure include those of Feshbach (by implication), Eason, Rosefielde, Conquest, Antonov-Ovseenko, Maksudov, Mace, and Diadkin; the approved estimates are those of Lorimer and Wheatcroft. Since this division parallels established lines of controversy, their essay in effect attempts to demonstrate that the Stalinist characterization of the human and material costs of forced industrialization is broadly correct. It is argued, purportedly on positivist grounds, that there are no compelling reasons to believe that more than a few million Soviet citizens perished from collectivization, Gulag, and the Terror $^{2}$ or that the Gulag forced labor population was abnormally high during the $1930 \mathrm{~s}^{3}$

1. Barbara Anderson and Brian Silver, "Demographic Analysis and Population Catastrophes in the USSR," Slavic Review 44 (Fall 1985): 517, 519. Anderson and Silver acknowledge that "the demographic history of the Soviet Union is marked by catastrophes. . . . [attributable in part to] the collectivization of agriculture and the famine." Like Wheatcroft, however, they avoid attributing a significant number of these catastrophic deaths to Gulag and the Terror and favor technical adjustments of the sort suggested by Lorimer that reduce famine and collectivization deaths to diminutive proportions (ibid., p. 517). Their comments about Lorimer's estimates as measures of "statistical consistency" rather than excess deaths should be read in this light (ibid., p. 520).

2. Lorimer estimated that there were 5.5 million excess deaths between 1 January 1929 and 1 January 1939 but refrained from firmly attributing them to collectivization, Gulag, and the Terror. See Frank Lorimer, The Population of the Soviet Union: History and Prospects (Geneva: League of Nations, 1946), p. 134. Wheatcroft frequently adopts the position that most estimated excess deaths have innocent causes but has recently been willing to concede the possibility of significant, policyrelated losses. See Stephen Wheatcroft, "Population Dynamic and Factors Affecting it, in the Soviet Union in the 1920s and 1930s," part 2, CREES Discussion Papers, Birmingham University (U.K.), 1976, p. 70; and idem, "New Demographic Evidence on Excess Collectivization Deaths: Yet Another Kliukva from Steven Rosefielde?" Slavic Review 44 (Fall 1985): 508.

3. Anderson and Silver, "Demographic Analysis and Population Catastrophes," p. 519. For a discussion of the normal level of Gulag forced labor see CIA, Crime and Punishment in the Soviet Union, GC79-10010, March 1979 (Confidential); U.S. House Subcommittee on Human Rights and 
These inferences are manifestly biased because Anderson and Silver do not evenhandedly consider the statistical strengths and weakness of the contending estimates. For example, while they excoriate the assumptions underlying estimates they disapprove, no attempt is made to demonstrate that the crucial adjustment to the 1926-1927 census mortality statistic that sustains Lorimer's and Wheatcroft's estimates, which Lorimer himself characterized as "arbitrary," is scientifically valid. ${ }^{4}$ The one-sidedness of their approach is shown further in the superficiality of their critique of my estimates, especially those pertaining to collectivization, Gulag, and Terror excess deaths.

In a series of articles I have demonstrated that the Soviet Union incurred between 3.5 million and 15 million more excess deaths from 1 January 1929 to 1 January 1939 than Lorimer had previously computed. ${ }^{5}$ These estimates are conceptually and methodologically identical with Lorimer's, differing only with regard to a few disputable statistics. I replace Lorimer's prewar natality and mortality data with more complete postwar series and adjust the 1926-1927 census mortality rate in accordance with Ansley Coale's calculations instead of Lorimer's. ${ }^{6}$ In addition I not only consider the 1939 census figure but also extend my data set to include the 1937 census population statistic reported by

International Organizations of the Committee of Foreign Affairs, Forced Labor in the Soviet Union, House of Representatives and Commission on Security and Cooperation in Europe, 9 December 1983, p. 103; Ger P. van der Berg, "The Stalinist System of Justice and Terror in Figures and Some Lessons for the Present Day," paper presented at the Third World Congress for Soviet and East European Studies, Washington, 30 October to 4 November 1985; and Steven Rosefielde, "Knowledge and Deception: Stalinist Industrialization Reconsidered," Soviet Studies (forthcoming, April 1987). Compare Gabor Tamas Rittersporn, "Soviet Officialdom and Political Evolution: Judiciary Apparatus and Penal Policy in the 1930s," Theory and Society 13 (1984): 211-237. Anderson and Silver incorrectly assert that "Rosefielde's main interest has been in estimating the size of the Soviet prison camp population" (Anderson and Silver, "Demographic Analysis and Population Catastrophes," p. 517). My main interest is in scientifically reconstructing the Soviet development experience and interpreting it from the standpoint of economic systems theory. They then quote Conquest to suggest that "we are unlikely to be able to deduce with any certainty the labour camp population from any of the demographic material presently available" (ibid., p. 519). This formulation misstates my intent. I can and do use the demographic evidence to demonstrate that my Gulag forced labor estimates are not disconfirmed by plausible estimates of contemporaneous excess deaths. Compare Robert Conquest, "Forced Labour Statistics: Some Comments," Soviet Studies 34 (July 1982): 438.

4. Lorimer, Population of the Soviet Union, p. 119. "These assumptions are obviously arbitrary. . . ." Compare Steven Rosefielde, "New Demographic Evidence on Collectivization Deaths: A Rejoinder to Steven Wheatcroft," Slavic Review 44 (Fall 1985): 514. The most Anderson and Silver venture in this regard is the hollow assertion that the logic of my critique of Lorimer's adjustment is "invisible." Anderson and Silver, "Demographic Analysis and Population Catastrophes," p. 523.

5. Steven Rosefielde, "Excess Mortality in the Soviet Union: A Reconsideration of the Demographic Consequences of Forced Industrialization 1929-1949," Soviet Studies 35 (July 1983): 385409; idem, "New Demographic Evidence on Collectivization Deaths 1929-33: The Demographic Evidence," Slavic Review 42 (Spring 1984): 83-88; idem, "New Demographic Evidence on Collectivization Deaths: A Rejoinder to Steven Wheatcroft," 509-516; idem, "Excess Deaths and Industrialization: A Realist Theory of Stalinist Economic Development in the Thirties," Journal of Contemporary History (forthcoming, July 1987); idem, "Knowledge and Deception"; idem, "An Assessment of the Sources and Uses of Gulag Forced Labour 1929-56," Soviet Studies 33 (January 1981): 51-87.

Anderson and Silver contend that Lorimer's methodology was only used as a test of statistical consistency, not excess deaths. This contention is both logically and factually specious. See Lorimer, Population of the Soviet Union, p. 133, "Actually, there is a discrepancy of about 5.5 million. One possible interpretation of this discrepancy is that it represents the magnitude of 'excess mortality' beyond that normally expected during the period of the collectivization of agriculture."

6. Ansley Coale's adjustment is an important and plausible component of Lorimer's more ambitious recomputation; see Lorimer, Population of the Soviet Union, p. 117. 
Antonov-Ovseenko. The estimates computed from these data reflect the official record with one definite and one possible exception. Coale's adjustment reduces officially implied excess deaths by 1.5 million people, ${ }^{7}$ and the suppressed 1937 population statistic cannot be independently confirmed.

Anderson and Silver do not dispute the intrinsic merit of this approach, but they claim nonetheless that my estimates are flawed because the official data I employ are deficient and because I fail to adjust vital statistics according to a right understanding of "the 'natural' course of demographic change." ${ }^{8}$ The data I employ, other than AntonovOvseenko's 1937 census statistic, are deficient, it is contended, not because they are unofficial, but because some official figures are "estimates" masquerading as "statistics" and others that purport to be "new" are not. More precisely, it is alleged that I have misconstrued Urlanis's natality rate estimates for 1931, 1933, and 1934 and treat them as if they were obtained directly from unpublished official demographic survey data when they are merely estimates based on the official figure for $1932 . .^{9}$ This criticism is easily disproved. The offending estimates are clearly bracketed and explained in the appropriate tables with the statement: "Bracketed natality rates are Urlanis's estimates." ${ }^{10}$ Suppose, however, that I had neglected to bracket Urlanis's estimates, would my results necessarily be biased? Anderson and Silver intimate that this is the case but a binary comparison of the official natality series I employ with Lorimer's reveals that the number of estimates he uses exceeds mine by 200 percent. ${ }^{11}$ His natality estimates for the critical years 1931 to 1934, moreover, exceed Urlanis's, generating higher and not, as my critics maintain, lower excess death counts. ${ }^{12}$

Anderson and Silver in raising the issue of estimates, of course, wish to make the larger point that during the chaos of collectivization, Gulag, and the Terror, Soviet demographic data collection was probably in disarray and, as a consequence, vital statistics should be regarded with suspicion. This council is well taken; however, not only does it tacitly concede my main point that extraordinary causes are apt to have calamitous effects, but it fails to take account of two important facts: First, as Rosa Sifman's anamnestic survey research has shown, the negative impact of demographic shocks are often dampened by compensatory fertility adjustments. Her data indicate that, although the natality rate did decline between 1930 and 1934, it decreased less rapidly than expected, in line with the intercensus trend rate. ${ }^{13}$ This suggests that it is unreasonable to assume, as Anderson and Siver do, that the official natality rates for 1932 and 1935, which are well below those implied by Sifman, are substantially overstated. Second, Urlanis's disclosure that the Soviet population in 1933 was 158 million instead of 165.7 million, as Stalin claimed, ${ }^{14}$ and similar estimates derived by van den Berg from Gertsenzon and Shliapochnikov's sentencing data clearly suggest that credible unpublished statistics were being

7. Compare Rosefielde, "Knowledge and Deception," table A1, with Rosefielde, "Excess Mortality in the Soviet Union," table 3, p. 388.

8. Anderson and Silver, "Demographic Analysis and Population Catastrophes," p. 517.

9. Ibid., pp. 523-524. The same argument is obliquely levied against my wartime natality estimates. See note 24 , below.

10. Rosefielde, "Excess Mortality in the Soviet Union," table 3, p. 388.

11. Ibid., table 2, p. 387. For a fuller discussion of the differences between these data see Rosefielde, "Knowledge and Deception."

12. Anderson and Silver, "Demographic Analysis and Population Catastrophes," p. 524.

13. Rosa Sifman, Dinamika rozhdaemosti v SSSR (Moscow: Statistika, 1974), figure 2, p. 43. Sifman uses the cumulative fertility behavior of twenty-nine-year-old women as her proxy for the real natality rate. Cf. Anderson and Silver, "Demographic Analysis and Population Catastrophes," pp. 530-531. For a more detailed discussion of this issue see Rosefielde, "Knowledge and Deception."

14. Stalin, "Otchetnyi doklad," 1934, p. 25, cited in Ger P. van den Berg, The Soviet System of Justice: Figures and Policy (Boston: Martinus Nijhoff, 1985), p. 176. 
collected during the early 1930s but were too politically sensitive to be publicly disclosed..$^{15}$ It may therefore be concluded that, while the reliability of Soviet vital statistics was impaired by the trauma of the times, they are probably more accurate than might be casually surmised.

The assertion that the vital statistics underlying my excess death estimate are not "new" is similarly misleading. As indicated above, they close gaps in the data base employed by Lorimer and may well take account of previously suppressed information. Anderson and Silver cannot deny the former, but they do assert without proof that the new vital statistics are merely recompilations of previously published series. They could be right, but this seems unlikely because the new and old statistics not only differ, but, as Urlanis has shown, the Soviets possess suppressed information, which they are occasionally willing to disclose. ${ }^{16}$

My new statistics are condemned further, because like Robert Conquest I believe that the 1939 census was fraudulent and compute a set of excess death estimates on the supposition that the 1937 census statistic published by Antonov-Ovseenko could be accurate. These calculations are summarily dismissed because Anderson and Silver assert that "this number . . . comes from the rumor mill in Soviet labor camps," 17 implying that Antonov-Ovseenko's sources are disreputable. A close reading of Portret tirana, however, indicates that the sources he describes,$^{18}$ which he maintains were his direct sources,${ }^{19}$ are credible. This does not prove that they are correct, but it suggests that it would be imprudent to dismiss them, especially since Wheatcroft admits that the 1939 census contains 1 million to 2.5 million "dead souls." 20

The allegation of Anderson and Silver that my excess death estimates are exaggerated because I misuse official data and mishandle missing observations thus cannot be objectively sustained. If my estimates do err the fault must lie elsewhere, in systematic biases that distort the official statistics I employ. This statement, then, brings us to the nub of the matter. Anderson and Silver insist that mortality rates based on official Soviet census, and noncensus estimates for the late 1920s, which crucially affect my excess death estimates, are wrong and they contend that they know how to correct these errors. ${ }^{21}$ They assert further that, if their adjustments are accepted, the 10.5 million excess deaths generated by the official statistics can be reduced to 5.5 million or less. ${ }^{22}$ Perhaps, but the burden is on them to prove it. In a matter as serious as the one under discussion, they cannot persuasively rest their case on Lorimer's authority when it is clear that his admittedly arbitrary adjustment was based on his subjective assessment of the probable

15. Ibid.

16. Rosefielde, "Excess Collectivization Deaths 1929-33," and "New Demographic Evidence," pp. 510-511. Compare Anderson and Silver, "Demographic Analysis and Population Catastrophes," p. 523.

17. Anderson and Silver, "Demographic Analysis and Population Catastrophes," pp. 525-526.

18. Anton Antonov-Ovseenko, Portret tirana (New York: Khronika, 1980), p. 211.

19. Antonov-Ovseenko, personal testimony.

20. Stephen Wheatcroft, "A Note on Steven Rosefielde's Calculations of Excess Mortality in the USSR, 1929-49," Soviet Studies 36 (April 1984): 278 and 281. Also see idem, "Population Dynamic and the Factors Affecting It, in the Soviet Union in the 1920s and 1930s," Part I, SIPS No. 1, University of Birmingham (U.K.), 1976, p. 36. Compare Anderson and Silver, "Demographic Analysis and Population Catastrophes," p. 526. "Although the 1939 census probably contains errors the existence and magnitude of other forms of misenumeration in that census have not been demonstrated."

21. Anderson and Silver, "Demographic Analysis and Population Catastrophes," p. 523. They simply accept Lorimer's "arbitrary" adjustment. It should also be observed that they restrict their discussion to the 1926-1927 census mortality rate, ignoring the fact that mortality rates for subsequent years belie their preferred adjustment.

22. Ibid., table 1 , column 3, p. 528; table 3, column 3, row 6, p. 531. 
consquences of Stalinism. With the limited information at his disposal in the 1940s it is not surprising that he was prepared to entertain the possibility that nearly half the excess deaths indicated by official data were explained by statistical aberrations, but with the advantage of hindsight we are not obliged to share his optimism. As I have previously observed, Soviet demographers have long been aware of Lorimer's adjustments but have not seen fit to alter their own judgment about the mortality rates prevailing in the late 1920s. Anderson and Silver find the logic of this rebuke to their preferred adjustment "invisible," ${ }_{23}$ but it seems to me that they are grasping at straws. The long and short of the matter is this: they cannot demonstrate that Lorimer's arbitrary adjustment is right, and they cannot legitimately fault me for disagreeing with them on the impartial statistical grounds they claim to uphold.

Anderson and Silver raise a variety of other objections against my calculations, including my excess death estimates for the $1940 \mathrm{~s},{ }^{24}$ but they are similarly insubstantial. The most important of these is the demonstration that excess death estimates are sensitive to assumptions in variables..$^{25} \mathrm{I}$ do not deny this truism. It is essential to recognize, however, that the method both Lorimer and I apply yields mean value estimates and that these estimates fall within the range of Anderson's and Silver's own sensitivity calculations. ${ }^{26}$ The variance around these means could be large, especially if the assumptions adopted are extreme, but there are no obvious reasons to believe that the true excess death count lies in the tail of the distribution required by their beliefs. Statistical uncertainty cannot be disregarded, but this verity neither validates their premises nor demonstrates that my estimates are biased. ${ }^{27}$

23. Ibid., p. 523.

24. Anderson and Silver contend that my excess death estimates for the 1940s, computed on the assumption that the 1939 census does not contain "dead souls" are wrong because the natality rates used for the years 1941-1945 are too high (this is the reason they assert my estimate is a population deficit, not an excess death statistic) and because Stephen Wheatcroft has uncovered other shortcomings (ibid., p. 522). The first objection is refuted by Rosa Sifman's anamnestic research. See Sifman, Dinamika rozhdaemosti v SSSR, p. 43. The second is disproven in Rosefielde, "Knowledge and Deception." Although, Soviet authorities have found it expedient to bury tens of millions of nonwar related excess dead in the "fog of war," we are not required to certify their deception, a point properly stressed by Nekrich. See Aleksandr Nekrich, Otreshis' ot strakha (London: Overseas Publication Interchange, 1979), p. 158.

25. This method is adopted because "a source-by-source or statistic-by-statistic approach is not the only way to evaluate the quality of demographic estimates" (Anderson and Silver, "Demographic Analysis and Population Catastrophes," p. 519). This statement is true, but evaluation and disproof are two separate things. Their sensitivity tests illuminate underlying uncertainties but do not establish their contention that their preferred estimates are right, or that mine are wrong.

26. In this regard it should be noted that while the purpose of Anderson's and Silver's sensitivity tests is to show that my findings are out of bounds, they actually confirm them. They write: "But it is clear that one would have to make an extraordinarily optimistic assumption about the 'normal' mortality rate, an assumption that the mortality rate was far lower than that reported for 1938-1939, to conclude that the number of excess deaths during 1927-1938 of persons who were alive in 1926 was in the neighborhood of 8 or 10 million" (ibid., p. 528). If the 5.2 million adult excess deaths I compute with the 1939 census are properly used as a standard of reference, they fall neatly within Anderson's and Silver's range of admissibility, 3.2 million to 5.5 million adult excess deaths (ibid., p. 529). See Rosefielde, "Excess Mortality in the Soviet Union," table 11, column 4, rows 3 and 4, p. 400. Lorimer's estimate similarly defined is 4.8 million excess fatalities. Anderson and Silver's reference to " 8 or 10 million" excess deaths wrongly refers either to my estimates based on the 1939 census including children or to my estimates based on the 1937 census.

27. Three additional miscellaneous criticisms warrant brief comment. Anderson and Silver assert, "Rosefielde has been inconsistent in his assumptions about the 1939 census. [He contends] that the 1939 census was an overcount. But earlier, when interpreting the 1939 census count of people working for pay Rosefielde treated the 1939 census as if it were a 'good' census" (Anderson and Silver, "Demographic Analysis and Population Catastrophes," p. 526). The purported contradiction 
Anderson and Silver contend that there are no objective grounds for believing that the "catastrophes" of the 1930s caused more than a few million collectivization and famine deaths or that the demographic record supports Gulag forced labor and Terror counts on the scale I estimate. Accordingly, they assert that their judgment is based solely on the "facts" and that differences between our results are attributable to my technical errors.

I have demonstrated above that this interpretation is wrong. My estimate of adult excess deaths between 1927 and 1939 based on the 1939 census falls squarely within the parameters established by their sensitivity estimates. ${ }^{28}$ The disparity between our assessments of Soviet demographic catastrophes thus does not rest, as they contend, on the alleged technical shortcomings of my calculations, but on differing premises. They believe without sufficient evidence that the tens of millions of excess deaths not related to the war indicated by official Soviet data between 1940 and 1949 are attributable to statistical error, ${ }^{29}$ that the 1939 census population statistic should be taken at face value despite compelling evidence to the contrary, and that the "arbitrary" adjustment made to the 1926-1927 mortality rate by Lorimer is sacrosanct. If these assumptions are granted it follows directly that most of the demographic losses incurred under Stalin are attributable

is entirely of their own contrivance. It does not necessarily follow that the census employment statistics are biased because the population aggregate is overstated. Moreover, I explicitly observed that the census employment statistics were incomplete because they omit unpaid penal workers; see Rosefielde, "Gulag Forced Labor," p. 73. On pp. 520-521 of their article Anderson and Silver split hairs about how best to define the concept of excess deaths. The purpose of this exercise is to imply that demographic analysis cannot support reliable assessments of fatalities caused by collectivization, Gulag, and the Terror. "We do not share Conquest's certitude about being able to estimate excess mortality from available demographic statistics" ("Demographic Analysis and Population Catastrophes," p. 519). Their argument is sophistic. Coroners' reports for the victims of collectivization, famine, Gulag, and the Terror would be ideal, but estimates based on Lorimer's method and other corroborating evidence will suffice. Finally, Anderson and Silver attack the credibility of my estimates by claiming that I do not clearly grasp the distinction between population deficits and excess mortality: "But Rosefielde has interpreted population deficits as if they were excess (actual) deaths. For example, at one point he writes that 'these data indicate that the Soviet Union experienced 37 million excess deaths during the 1940s.' In fact, the figure to which he refers is an estimate of a population deficit, not of excess deaths" (ibid., p. 522). Both the assertions, that I have not clearly elaborated the distinction between these concepts and that the figure in question is a population deficit, are nonsense. With regard to the former see Rosefielde, "Excess Mortality in the Soviet Union," p. 385. Anderson and Silver do not spell out the rationale for their second allegation, but their text implies that they believe my natality statistics are unreliable: "It is extremely misleading to interpret population deficits as excess deaths because the population deficit includes . . . births that did not occur" (Anderson and Silver, "Demographic Analysis and Population Catastrophes," p. 522). This characterization is deceptive. It is predicated on the erroneous assertion that excess mortality estimates are only valid if birth statistics are completely accurate. Population deficits are distinguished from excess mortality estimates not by the precision of the birth data, but by the fact that the former are projections, whereas the latter are based on ex post facto statistics adjusted where necessary for missing observations. A glance at my computations reveals that I use ex post facto natality statistics, rather than projections, which yield excess mortality estimates as claimed, not population deficits. See Rosefielde, "Excess Mortality in the Soviet Union," table 5, p. 393. Anderson and Silver demur because they believe my wartime natality rates are unreliable. Perhaps they are, but as a comparison between my natality rates and those employed by Lorimer for an earlier period demonstrate this does not mean that my estimates must be interpreted as population deficits; see my "Excess Mortality in the Soviet Union," table 5, p. 393, and table 2, p. 387.

28. See note 26 .

29. Rosefielde, "Excess Mortality in the Soviet Union," table 12. Cf. Jean-Claude Chesnais, "Some Peculiarities of Eastern Europe and Soviet Population Trends," paper presented at the Third World Congress for Soviet and East European Studies, Washington, 30 October to 4 November 1985, pp. 6-8. 
to the war and that only negligible numbers of excess dead can be ascribed to Gulag and the Terror.

Alternatively, if these assumptions are rejected, as I have argued elsewhere they should be, my interpretation of the collectivization, famine, Gulag, and Terror catastrophes is sustained. The controversy over the demographic consequences of Stalinism in the final analysis, thus, cannot be reduced to issues of method or technical misunderstanding. It is a substantive dispute that depends on the assessment of the catastrophic potential of Stalin's policies and the critical statistics that bear on them. This permits Anderson and Silver and me to debate the weight of the evidence but does not allow them to assert that my estimates misrepresent the official demographic record or are technically flawed because they are inconsistent with their premises. 